\title{
Considerations on Strengthening the Management of National Defense Intellectual Property Rights in Military Academies
}

\author{
Zehao Pang ${ }^{1, a^{*}}$, Rui Ding ${ }^{2}$, Huaijun Zhou ${ }^{3}$

\begin{abstract}
${ }^{I}$ Department of Information Communication, Chinese people's Liberation Army National University of Defense Technology, Jiang'an District, Wuhan, Hubei, China

${ }^{2}$ Department of Information Communication, Chinese people's Liberation Army National University of Defense Technology, Jiang'an District, Wuhan, Hubei, China

${ }^{3}$ Department of Information Communication, Chinese people's Liberation Army National University of Defense Technology, Jiang'an District, Wuhan, Hubei, China

a*Howard_Pangzer@163.com
\end{abstract}

\begin{abstract}
On the basis of combing the development of national intellectual property rights and national defense intellectual property rights, through the comparison between national defense intellectual property and national intellectual property, and through the comparison between military academy intellectual property and local university intellectual property, focusing on enhancing the level and efficiency of scientific and technological innovation in military colleges and universities and improving the independent innovation ability of military colleges and universities, this paper analyzed the prominent problems existing in the intellectual property rights of military colleges and universities. Aiming at the particularity of objects and requirements of national defense intellectual property management, around the key links of organization management system, coordination mechanism, management system, personnel training and so on, this paper put forward countermeasures and suggestions for the problems.
\end{abstract}

Keywords : Military Academies, National Defense Intellectual Property Rights, Intellectual Property Management

\section{加强军队院校国防知识产权管理的几点思考}

\author{
庞泽豪 ${ }^{1, a^{*}}$ 丁 锐 ${ }^{2}$ 周怀军 3
}

${ }^{1}$ 国防科技大学信息通信学院, 江岸区, 武汉, 湖北, 中国

2 国防科技大学信息通信学院, 江岸区, 武汉, 湖北, 中国

3 国防科技大学信息通信学院, 江岸区, 武汉, 湖北, 中国

$a^{*}$ Howard_Pangzer@163.com

\section{摘要}

本文在梳理国家知识产权和国防知识产权建设发展脉络的基础上，通过国防知识产权与国家知识产权、军队院 校知识产权与地方高校知识产权建设的对比, 分析提出军队院校知识产权存在的突出问题, 着眼增强军队院校 科技创新水平和效率、提高军队院校自主创新能力, 针对国防知识产权管理对象与要求的特殊性, 围绕组织管 理体系、协调机制、管理制度、人才培养等关键环节提出对策建议。

关键词: 军队院校; 国防知识产权; 知识产权管理 


\section{1. 前言}

知识产权是重要的战略资源 $[1]$ 。国防知识产权作 为国家知识产权的重要组成部分，是国防发展的基础, 也是国防科技核心竞争力的集中体现。军队院校作为 国防知识创新和技术创新的重要力量, 承担着与军队 使命有关的基础性、战略性、前瞻性科学研究和技术 开发。其产出的具有自主知识产权的高水平研究成果 管理、转化、保护等工作, 将是军队院校国防知识产 权管理的创新基础性、重点关键性工作，和军队院校 科技创新能够行稳致远的重要环节。当前, 军队院校 面临体系重塑和职能任务调整、为建设世界一流军队 输送人才和提供智能支持等使命, 科技创新的任务更 加艰巨。同时, 随着国家知识产权战略和国防知识产 权战略的实施, 国防知识产权突破了一系列瓶颈难题, 成功地开展了相关试点示范工作, 催生了一批核心知 识产权, 对国防科技和武器装备建设发挥了重要作用。 但是作为国防知识产权重要组成部分的军队院校知 识产权管理, 还存在着 “重数量轻质量” “重申请轻实 施” 等突出矛盾问题,与国防和军队建设需要不适应, 必须要深入贯彻《国防知识产权战略实施方案》, 聚 焦以人工智能技术为标志的新一代信息技术加大创 新力度, 提高国防科技自主创新能力, 运用优质科研 成果为国防和军队建设、经济社会发展服务。

\section{2. 军队院校知识产权管理现状和问题}

在国防专利制度基础上通过长期建设, 特别是国 防知识产权战略贯彻实施, 军队院校在知识产权管理 上取得长足进步, 知识产权意识得到提升, 在军事科 技创新、人才培养等方面做出了杰出贡献 ${ }^{[2]}$ 。但与国 内地方高校、高科技新型企业相比, 军队院校知识产 权管理还存在许多短板和亟待解决的问题。

一是知识产权管理观念亟待更新。军队院校知识 产权管理受多种因素的制约, 理念上仍然存在重评奖 轻产权、重申请轻转化、重数量轻质量等现象, 尤其 以部分任职教育和指挥类教育院校为典型, 对知识产 权的保护观念认识迟滞, 组织建设的知识产权保护体 系不够完整。根据人才评价制度导向, 军队院校科研 人员发展与成果奖励愈发紧密相连, 因此对科研成果 获奖十分重视, 科研人员取得创新成果后, 为了成果 评奖, 首先进行成果鉴定而不是申请专利, 这就极大 的增加了知识产权流失风险。例如公开发表论文造成 成果失去新颖性和独有性, 导致不能申请专利; 即便 成果能够申请专利, 但对后续专利成果的转化不够重 视, 导致大批创新成果成为了单位的荣誉, 而并不能 真正得到转化应用, 发挥创造效益, 提高专利质量。

二是知识产权法规制度急需完善。长期以来, 国 家教育部、科技部、知识产权局等部门制定了《高等 学校知识产权保护管理规定》《高等学校知识产权管 理规范》《关于提升高等学校专利质量促进转化运用 的若干意见》等多部规范高校知识产权管理的法规,
不少地方高校也出台了本校的知识产权管理规定。但 军队院校知识产权管理法规制度建设明显滞后, 专门 法律法规非常有限, 对知识产权的权属认定、申请保 护、转化流程、奖励办法等重要内容缺少具体规定, 通常通过《国防专利条例》等国防知识产权全局性、 通用性政策法规进行规范。例如军队院校科研管理中 一个重要环节就是成果鉴定和转化, 此环节涉及的申 请专利和技术保密等知识产权管理并没有制定独立 的规章规定来系统性约束和限定, 更多的是参照科研 管理规定中的 “只言片语” 来对知识产权进行管理, 无法前瞻性和系统性阐述知识产权管理的专业性和 重要性, 淡化了科研管理中知识产权管理的重要性, 可见知识产权管理与科研工作管理脱节。对于军民通 用的普通知识产权则借鉴地方相关法规, 缺少适用于 军队院校科研成果特殊性的法律依据。

三是知识产权体制机制需要健全。无论是国家知 识产权战略要求, 还是军队院校知识产权管理客观实 际, 均需要专门的管理机构和人员。由于军队编制体 制的约束, 军队院校一般没有设立专门的知识产权管 理机构, 知识产权管理业务归属科研管理归口部门代 为行使。目前个别院校虽建立了一些专门的知识产权 研究机构, 但本质上仍是将其并入科技成果管理范畴, 大大弱化了知识产权管理地位, 远未能满足军队院校 知识产权管理的现实需要, 限制了知识产权管理作用 的发挥 ${ }^{[3]}$ 。此外, 个别院校建立的知识产权管理机构 主要围绕国防专利管理, 管理的范畴和对象具有很大 的局限性, 如国防科技大学专利服务中心, 主要围绕 国防专利代理、软件著作权登记代理、专利检索、专 利信息分析、专利预警、知识产权战略研究和咨询等 开展服务, 在专利申请、专利宣传、专利代理人培养、 专利文献、专利成果、成果转化、知识产权登记以及 归档和数据库管理等方面缺少全方位管理和服务机 制, 需要完善形成科学合理的管理与服务体制, 对防 范知识产权的流失, 创造成体系的国防知识产权保护 做好先锋模范作用。

\section{3. 加强军队院校国防知识产权管理的建议}

针对军队院校国防知识产权管理存在的问题, 着 眼提升国防知识产权管理效益, 完善科技活动中知识 产权管理体制机制，健全军转民、民参军和军民深度 融合相关举措, 不仅有利于促进科技成果的双向转化, 也有利于增强科研人员的创新活力, 推动军队院校科 技创新，在军民融合的进程中保持军队院校的核心竞 争优势。

\section{提出以下几点对策和建议:}

一是健全专职组织管理体系。健全的组织机构是 成功推行知识产权制度的重要保障。国家教育部等三 部门印发的《关于提升高等学校专利质量促进转化运 用的若干意见》提出, 高校要成立知识产权管理与运 营领导小组或科技成果转移转化领导小组, 统筹科研、 知识产权、国资、人事、成果转移转化和图书馆等有 
关机构。国家相关部委对地方高校知识产权管理体系 建设的指导性意见, 对于军队院校知识产权管理体系 建设具有重要的参考价值。军队院校要按照国防知识 产权管理体系建设的总体布局, 建立专门的知识产权 管理部门, 设立专门和专职知识产权管理人员, 进一 步完善知识产权转移转化评估、激励等管理制度, 设 立知识产权保护专项经费, 完善知识产权保护软硬件 条件，有效改变目前多头管理、非专业人员管理、无 人管理的现状。有条件的军队院校可以借鉴知识产权 领导小组、知识产权管理办公室等组织形式, 建立专 门管理机构, 并设专人负责制订学院知识产权工作的 具体规划, 统管本学院的知识产权申请、审查、鉴定、 评估、登记、注册和监督管理、科技奖励、成果转化 等工作, 以及知识产权争议和纠纷、宣传教育和普及 工作，建立涵盖知识产权计划拟制、分类审批、效益 评估、年度报告总结等的全链条管理体系, 强化与军 队有关知识产权归口管理部门的沟通协调, 建立与政 府、企业和科研院所之间的融合及交流机制, 提高院 校知识产权综合管理效益。

二是完善闭环管理协调机制。国家标准《高等学 校知识产权管理规范》明确, 要形成科技创新和知识 产权管理、科技成果转移转化相融合的统筹协调机制 [4]。军队院校应建立健全知识产权规划计划、过程管 理和工作绩效考评闭环管理机制, 确保知识产权管理 高效运行。首先要建立规划计划机制, 统筹规划计划 院校知识产权管理的指导原则、建设目标、重点任务、 阶段划分和相关保障等事宜。其次要完善过程管理机 制, 按照科研项目立项、实施、验收阶段实施标准, 对项目各个阶段知识产权管理活动进行规划, 全程掌 握项目中知识产权动态及发展, 建立利益调节等激励 机制, 激励知识产权的创造和运用。再者要建立工作 绩效考评机制，建立完善的知识产权管理评估机制和 考评体系, 完善各项知识产权工作的绩效考评标准、 指标和办法, 重点关注科研项目申报、研究 (制) 过 程中运用知识产权能力的评价, 以及对科研管理过程 中知识产权管理的评价, 使评估和考核结果同科研管 理人员的职称、职务的晋升及奖惩等有机结合起来; 最后要拓宽资金保障, 资金是开展知识产权管理的基 本保障, 设立知识产权专项基金, 用以支持专利维护、 适应性研发和工程化实验等方面, 形成知识产权从研 发到工程化全流程资助机制, 调动科研管理人员技术 创新的积极性。

三是完善管理制度体系。完善的政策与管理制度 是规范科技人员、管理人员行为的准则。制定完整配 套的知识产权保护、管理办法, 是军队院校知识产权 效益发挥的重要制度保障。应以国防知识产权法规体 系框架为依据, 以国家教育部发布的《高等学校知识 产权保护管理规定》为借鉴, 依据国防知识产权顶层 法律法规, 细化明确知识产权管理在军队院校管理中 的地位、意义、方法和手段等, 为提高知识产权管理 效益提供指导性意见。围绕军队院校知识产权登记与 界定、申报审核、归属、合同审核、转化与评价激励、
档案管理与保密等各活动环节、各业务领域, 制定出 台军队院校知识产权管理法规制度, 为加强和规范知 识产权管理提供制度依据。例如知识产权归属政策的 制定，应立足保护所有者权益与鼓励技术扩散相结合， 保护投资者与鼓励发明人相结合的原则，兼顾国家、 单位和个人的利益, 明确有偿使用、无偿使用条件和 范围, 充分考虑监管者的职责履行和调动知识产权所 有者的积极性, 适当放权与适度监管, 形成完备的知 识产权归属政策体系。

四是加强专门人才培养。人才是创新的根基, 知 识产权人才是激励创新、引领创新、保护创新和服务 创新的专门人才。国防知识产权人才对专业知识的复 合性、综合性要求高, 以工科电子通信专业为例, 不 仅需要掌握该专业的知识, 还需要掌握法学、经济学、 管理学、军事学等专业的知识 $[5]$ 。国防知识产权的专 业性、综合性和特殊性, 要求具有一支专门的人才队 伍。首先要围绕院校相关人员进行知识产权专题培训, 从加大宣传培训力度入手, 增强院校科研人员知识产 权意识, 营造尊重知识产权的良好氛围, 提高科研人 员的知识产权业务创新能力。针对知识产权管理方面 的领导干部、专业人员、科研技术人员等不同层次和 岗位工作内容和要求, 采用培训班、讲座、研讨会、 国内外交流等多种培训形式开展知识性、技能性培训, 增强全体人员知识产权保护意识和能力。其次是布局 学科专业, 高等教育学科专业是人才培养的基础和载 体。军队院校要充分发挥人才培养的主渠道作用, 借 鉴地方高校知识产权学科建设成果, 拓展国防知识产 权学科专业建设, 将知识产权业务能力列入人才培养 方案, 将知识产权课程列入人才培养计划, 确保国防 知识产权人才培养具有明确的目标、高效的资源配置, 与院校的科研规划相适应。再次, 要加强知识产权管 理师资建设。采取专兼结合、军地联合的办法, 考虑 科研工作周期性、规划性管理机制，以及科技人员现 实需求, 培养一批业务精、教学能力强的国防知识产 权教师教学队伍。教学队伍的兼职教师可以从地方大 学和专业知识产权管理机构聘请, 也可以与地方大学 或者专业机构签订合作协议, 委托培养专业教师人才。

\section{4. 结语}

国防知识产权经过三十年的发展，特别是 2009 年国防知识产权战略实施以来, 取得了显著成绩。但 由于军队院校国防知识产权管理对象与要求的特殊 性, 与国家知识产权建设和地方高校知识产权建设相 比较, 还存在不同程度的滞后。随着国防科技创新的 迫切需求, 紧紧围绕军队院校知识产权中暴露的问题, 深入探讨军队院校科技创新中的知识产权管理, 研究 提出增进军队院校知识产权管理效益的对策建议, 对 于增强军队院校科技创新水平和效率、提高军队院校 自主创新能力, 具有重要的意义和价值。 


\section{项目基金}

本文为武器装备技术基础项目《国防科技 大学军民融合领域知识产权转化工作机制研 究》(181GF51002)的阶段性成果之一。

\section{REFERENCES}

[1] Lishun, W., Yuan, G. (2012) Research on the development status and Countermeasures of national defense intellectual property in China. Defence Industry Conversion in China, 09: 28-30.

[2] Qiang, H., Yugang, W., Hengxin, W. (2016) Research on the application management of intellectual property in military colleges and Universities. Education and Teaching Forum, 09: $126-127$.

[3] Xiaowen, C. (2015) Research on intellectual property management in Military Colleges. Science and Technology Innovation Herald, 26: 207-208.

[4] Ministry of Education., National Intellectual Property Administration., Ministry of Science and Technology. (2020) Some opinions on improving the patent quality and promoting the transformation and application in Colleges and universities. http://www.gov.cn/zhengce/zhengceku/202002/21/content_5481750.htm.

[5] Liqing, R., Xiaobo, L., Lili, Gao. (2015) Research on the problems and countermeasures of intellectual property education in military engineering colleges. Education and Teaching Forum, 44: 168-169. 